\title{
COMPARISON BETWEEN MEASUREMENTS OBTAINED WITH THREE DIFFERENT PERINEOMETERS
}

Patrícia Brentegani Barbosa, Maíra Menezes Franco, Flaviane de Oliveira Souza, Flávia Ignácio Antônio, Thaís Montezuma, Cristine Homsi Jorge Ferreira

\author{
doi: $10.1590 / \mathrm{S1807-59322009000600007}$
}

Barbosa PB, Franco MM, Souza FO, Antônio FI, Montezuma T, Ferreira CHJ. Comparison between measurements obtained with three different perineometers. Clinics. 2009;64(6):527-33.

OBJECTIVE: To analyze the results obtained in the evaluation of intra-vaginal pressure using three different brands of perineometers in nulliparous volunteers.

MATERIALS AND METHODS: Twenty nulliparous women with no anatomical alterations and/or dysfunction of the pelvic floor were enrolled in our study. All the women had the ability to voluntarily contract their PFM (Pelvic Floor Muscles), as assessed by digital palpation. The intra-vaginal pressure was assessed using three different brands of perineometer (Neurodyn Evolution ${ }^{\mathrm{TM}}$, SensuPower ${ }^{\mathrm{TM}}$ and Peritron ${ }^{\mathrm{TM}}$ ). Each volunteer was evaluated on three alternate days by a single examiner using a single brand of perineometer on each day. In the assessment, the volunteers were required to pull (contract) their PFM in and up as strongly as possible 3 times and to sustain the contraction for 5 seconds, with an interval of 30 seconds between each pull. For the statistical analysis, a concordance correlation coefficient was used to compare the values that were obtained with each brand of perineometer.

RESULTS: A moderate concordance (0.51) was found between the results from the Peritron ${ }^{\mathrm{TM}}$ and Neurodyn ${ }^{\mathrm{TM}}$ perineometers, a fair concordance $(0.21)$ between the Peritron ${ }^{\mathrm{TM}}$ and SensuPower ${ }^{\mathrm{TM}}$ brands and a poor concordance $(0.19)$ between the Neurodyn ${ }^{\mathrm{TM}}$ and SensuPower ${ }^{\mathrm{TM}}$ brands.

CONCLUSION: The concordance of the measurements of the intra-vaginal pressure ranged from poor to moderate, suggesting that perineometers of different brands generate different results.

KEYWORDS: Physiotherapy; Pelvic floor; Evaluation; Reliability; Woman.

\section{INTRODUCTION}

The evaluation of the pelvic floor is crucial to identify dysfunctions that may affect the quality of life of women and contribute to problems such as stress urinary incontinence (SUI), fecal incontinence and sexual dysfunction. ${ }^{1}$ It is used as a tool for monitoring the clinical results that are achieved through rehabilitation methods of the muscles of the pelvic floor (PFM). It is also used as a teaching tool and as motivation for carrying out the training exercises. ${ }^{2,3}$

Department of Biomechanics, Medicine and Rehabilitation of the Locomotor Apparatus, Faculty of Medicine of Ribeirão Preto - Ribeirão Preto/ SP- Brazil.

Email: patricia_brentegani@yahoo.com.br

Tel: 55113602.1000

Received for publication on November 24, 2008

Accepted for publication on March 10, 2009
Several methods have been recommended by different authors for the evaluation of PFM, such as electromyography, vaginal cones, digital palpation, perineometer measurements, ultrasonography and magnetic nuclear resonance. ${ }^{4,5}$ However, the most often used functional assessment methods are the digital palpation and perineometer measurement methods because they are low in cost, easily applicable and well accepted by women in general. ${ }^{6}$

The perineometer, through a compressible vaginal catheter that is connected to a manometer, measures the increase of intravaginal pressure that is produced by the contraction of PFM, usually in $\mathrm{cmH}_{2} \mathrm{O}$ or in $\mathrm{mmHg}{ }^{7}$ The advantage of this tool is to quantitatively measure, in an indirect way, both strength and muscular endurance. The direct measurement of muscle strength is obtained using the dynamometer, and the unit measurements are given in Newtons. 
The validity of measurements that are obtained through the perineometer is limited for the more than $30 \%$ of women who have poor voluntary motor control for PFM contractions. ${ }^{8-11}$ This is justified by the fact that increases in vaginal pressure are not always directly related to PFM contractions, and, once the contraction of the abdominal muscles begins, relevant pressure increases are recorded by the vaginal perineometer.

Despite the limitations of the perineometer measurements, several studies show good intra-examiner reliability using the same brand of perineometer, ${ }^{7,12-15}$ provided that they follow criteria that are already well established in the literature. ${ }^{5,12,16,17}$ These criteria include carrying out vaginal palpation before the use of the perineometer to make sure that the woman is able to correctly contract the PFM, observing the cranial movement of the vaginal catheter during the measurement of muscle contraction and not considering the contractions that are associated with the Valsalva maneuver or retroversion of the hip. ${ }^{18-21}$

There is minimal literature that assesses the reliability of measurements that are obtained with different brands of perineometer. Bo et al. (2005) ${ }^{21}$ investigated the reliability of measurements that were obtained by perineometers that have probes of different sizes. These include a fiberoptic microtip transducer (Camtech AS, Norway), which is $6.7 \mathrm{~cm}$ in length and has a diameter of $1.7 \mathrm{~cm}$, and the Peritron ${ }^{\mathrm{TM}}$, which is 10.8 $\mathrm{cm}$ in length and has a diameter of $2.8 \mathrm{~cm}$. Twenty nulliparous women volunteered to be evaluated, and the results indicated a low concordance between the measurements that were obtained with the two instruments. The fiberoptic microtip transducer (Camtech AS, Norway) and Periton ${ }^{\mathrm{TM}}$ have the same unit of measurement $\left(\mathrm{cmH}_{2} \mathrm{O}\right)$ and have been used in various international clinical trials., ${ }^{72-15}$

In Brazil, the abovementioned instruments need to be imported and are expensive compared to national products. However, Brazilian instruments use different units of measurement, which complicates any comparison between measurements obtained with the use of both Brazilian and imported brands. It is unclear whether there is any correlation between measurements from domestic and imported equipment, even when using probes that have similar diameters.

The lack of studies that compare results from both Brazilian and imported perineometers justifies the importance and originality of this research, which aims to compare data obtained from Brazilian perineometers that have different units of measurements with readings from imported equipment, which are often used in international studies.

The objective of this study is to verify the correlation between measurements that were obtained from three different brands of equipment.

\section{MATERIALS AND METHODS}

\section{Design and Subjects}

This is an observational study that was conducted at the Centro de Reabilitação (CER) do Hospital das Clínicas da Faculdade de Medicina de Ribeirão Preto da Universidade de São Paulo (HCFMRP-USP), after being approved by the Research Ethics Committee of the institution.

We used a convenience sample group that consisted of 20 volunteer women who were undergoing treatment at the CER and who agreed to participate in the study after being made aware of the details of this research. All participants signed an informed consent form.

\section{Inclusion Criteria}

The women met the following inclusion criteria: age between 18 and 35 years, normal body mass index (BMI $<25 \mathrm{~kg} / \mathrm{m}^{2}$ ), nulliparous and not pregnant, able to achieve a correct contraction of the PFM, without any anatomical alterations or any pelvic floor dysfunctions, having made at least one gynecological appointment in the past twelve months and having no symptoms of vaginal infection, such as itching, stinging and/or vaginal discharge of fetid odor.

\section{Exclusion Criteria}

The exclusion criteria included women who did not attend the scheduled days of assessment to submit to the examination and women who exhibited intolerance to the condoms that covered the vaginal probe of the perineometers and/or an allergy to the gel that was used in the procedure.

\section{MATERIALS}

The perineometers listed below were used in the assessments:

\begin{tabular}{llll}
\hline Perineometer & Brand & Catheter Length & $\begin{array}{l}\text { Catheter } \\
\text { Diameter }\end{array}$ \\
\hline Neurodyn $_{\text {Evolution }^{\mathrm{TM}}}$ & IBRAMED & $9.3 \mathrm{~cm}$ & $3.2 \mathrm{~cm}$ \\
SensuPower $^{\mathrm{TM}}$ & Cardio-Design & $10.8 \mathrm{~cm}$ & $3 \mathrm{~cm}$ \\
Peritron $^{\mathrm{TM}}$ & & & $2.8 \mathrm{~cm}$ \\
\hline
\end{tabular}

The equipment was new, and the calibration had been certified by the equipment manufacturers. The Peritron ${ }^{\mathrm{TM}}$ (Cardio-Design, Australia) measures the contraction in $\mathrm{cmH}_{2} \mathrm{O}$, the Neurodyn ${ }^{\mathrm{TM}}$ (Ibramed, Brazil) in $\mathrm{mmHg}$ and Sensu Power ${ }^{\mathrm{TM}}$ (Kroman, Brazil) in Sauers. The first brand 
is Australian, and the second and the third brands are Brazilian.

The Neurodyn ${ }^{\mathrm{TM}}$ (Ibramed) equipment had its catheter inflated to $25 \mathrm{mmHg}$ as per the manufacturer's recommendation.

\section{Procedures}

The assessment of the muscles of the pelvic floor was made with the patient in a gynecological position, with bare abdominal regions, pelvic floor and legs. This position provides a more accurate assessment of the contraction of isolated musculature. ${ }^{3}$

The intra-vaginal pressure generated by the contraction of the PFM of the participants was assessed using the three different perineometers, each consisting of a vaginal probe that was connected to an electronic device, which indicates the values of contraction. Each volunteer was evaluated on three alternate days, by a single examiner, with a single brand of perineometer on each day. The Neurodyn Evolution $^{\mathrm{TM}}$ (Ibramed, Brazil) was used on the first day, the Sensu Power ${ }^{\mathrm{TM}}$ (Kroman, Brazil) was used on the second day, and the Peritron ${ }^{\mathrm{TM}}$ (Cardio-Design, Australia) was used on the third day.

The patients had been previously assessed by digital palpation, made aware of the procedure and advised on the correct way to maintain PFM contractions. Following the introduction of the catheter, the instruments were calibrated to zero before the measurement of the intra-vaginal pressure during vaginal muscle contraction.

During the assessment, the volunteers were required to pull (contract) their PFM in and up as strongly as possible 3 times and to sustain the contraction for 5 seconds. We used an interval of 30 seconds between the contractions.

The average peak value of the three contractions was used to compare the results from the three instruments.

The middle of the probe was inserted $3.5 \mathrm{~cm}$ into the vagina. We only considered those contractions for which it was possible to observe the cranial movement into the vagina. Any contractions for which a retroversion of the hip or a Valsalva maneuver was noticed were discounted. ${ }^{15-17}$

\section{Statistical Analysis}

All the units of measurement from the Neurodyn ${ }^{\mathrm{TM}}$ (Ibramed, Brazil) and the Sensu Power ${ }^{\mathrm{TM}}$ (Kroman, Brazil) were first transformed into $\mathrm{cmH}_{2} \mathrm{O}$ to allow comparison of their results with those recorded from the Peritron ${ }^{\mathrm{TM}}$ (CardioDesign, Australia).

With regard to the SensuPower ${ }^{\mathrm{TM}}$ (Kroman, Brazil) instrument, which measures the pressure in Sauers, the equivalent reading in pounds per square inch (psi), according to the manufacturer's manual, was obtained through a simple linear regression where $y=a+b x$, with the estimated parameters $a=0.2127$ and $b=0.02966$. The variables $x$ and $\mathrm{y}$ correspond, respectively, to the value of the variable in Sauers and to the value in psi.

To transform the resulting value from psi into $\mathrm{cmH}_{2} \mathrm{O}$, we used another linear regression. This time, the regression was $y=a+b x$, with $a=-0.001278, b=70.3091061, x=$ the value in psi and $\mathrm{y}=$ output value in $\mathrm{cmH}_{2} \mathrm{O}$.

In order to transform the unit of measurement from the Neurodyn ${ }^{\mathrm{TM}}$ (Ibramed, Brazil) from $\mathrm{mmHg}$ to $\mathrm{cmH}_{2} \mathrm{O}$, a linear regression was used, where $\mathrm{y}=\mathrm{a}+\mathrm{bx}$, with $\mathrm{a}=$ $0.001056688, \mathrm{~b}=1.359508306, \mathrm{x}=$ the value in $\mathrm{mmHg}$ and $\mathrm{y}=$ the output in $\mathrm{cmH}_{2} \mathrm{O}$.

Our statistical analysis used the concordance correlation coefficient $(\rho)^{22}$. The nearer the coefficient was to 1 , the greater the concordance among measures from within the same class.

Reliability values were interpreted according to the scale by Altman $[1997]^{23}$, where $<0.20$ is considered poor, 0.21 0.40 fair, 0.41- 0.60 moderate, $0.61-0.80$ good and 0.81-1.00 very good.

\section{RESULTS}

The participants in this study had an average age of 23.85 years, came from a middle-tier socioeconomic level and had some higher education.

The averages of the three maximum contractions performed by the participant with the three types of equipment, namely, Neurodyn ${ }^{\mathrm{TM}}$ (Ibramed, Brazil), SensuPower ${ }^{\mathrm{TM}}$ (Kroman, Brazil) and Peritron ${ }^{\mathrm{TM}}$ (CardioDesign, Australia) are shown in Table 1.

The correlations between the instruments are shown in Figures 1, 2 and 3 . There was a moderate concordance $(0.51$, CI of 95\%: 0.11, 0.77) between the results obtained with the Neurodyn ${ }^{\mathrm{TM}}$ (Ibramed, Brazil) and Peritron ${ }^{\mathrm{TM}}$ (CardioDesign, Australia) perineometers, a fair concordance (0.21, CI of 95\%: 0, 08; 0.34) between the SensuPower ${ }^{\mathrm{TM}}$ (Kroman, Brazil) and Peritron ${ }^{\mathrm{TM}}$ (Cardio-Design, Australia) brands and a poor concordance $(0.19, \mathrm{CI}$ of $95 \%$ : $0.07,0.30)$ between the Neurodyn ${ }^{\mathrm{TM}}$ (Ibramed, Brazil) and SensuPower $^{\mathrm{TM}}$ (Kroman, Brazil) brands.

\section{DISCUSSION}

Our results suggest significant differences in the measurement of maximum PFM contractions from the three different instruments.

Several factors may have contributed to these results, 
Table 1 - Vaginal squeeze pressure measurement $\left(\mathrm{cmH}_{2} \mathrm{O}\right)$ using the Neurodyn, Sensu Power and Peritron

\begin{tabular}{lccc}
\hline Participant & Neurodyn $^{\mathrm{TM}}$ & SensuPower $^{\mathrm{TM}}$ & Peritron $^{\mathrm{TM}}$ \\
\hline 1 & 41.69 & 74.53 & 27.13 \\
2 & 20.39 & 59.06 & 33.30 \\
3 & 54.83 & 124.45 & 70.47 \\
4 & 42.60 & 79.45 & 41.43 \\
5 & 21.30 & 57.65 & 26.77 \\
6 & 81.57 & 118.82 & 36.83 \\
7 & 29.46 & 79.45 & 44.33 \\
8 & 48.04 & 111.09 & 50.57 \\
9 & 29.91 & 73.82 & 50.10 \\
10 & 41.24 & 77.34 & 66.87 \\
11 & 39.88 & 114.6 & 37.80 \\
12 & 29.46 & 70.31 & 33.23 \\
13 & 45.32 & 74.53 & 42.77 \\
14 & 51.66 & 133.59 & 76.43 \\
15 & 45.77 & 63.28 & 47.27 \\
16 & 28.55 & 61.17 & 20.77 \\
17 & 35.80 & 89.29 & 39.70 \\
18 & 64.35 & 99.84 & 64.37 \\
19 & 69.34 & 114.60 & 75.73 \\
20 & 43.50 & 56.95 & 25.80 \\
\hline
\end{tabular}

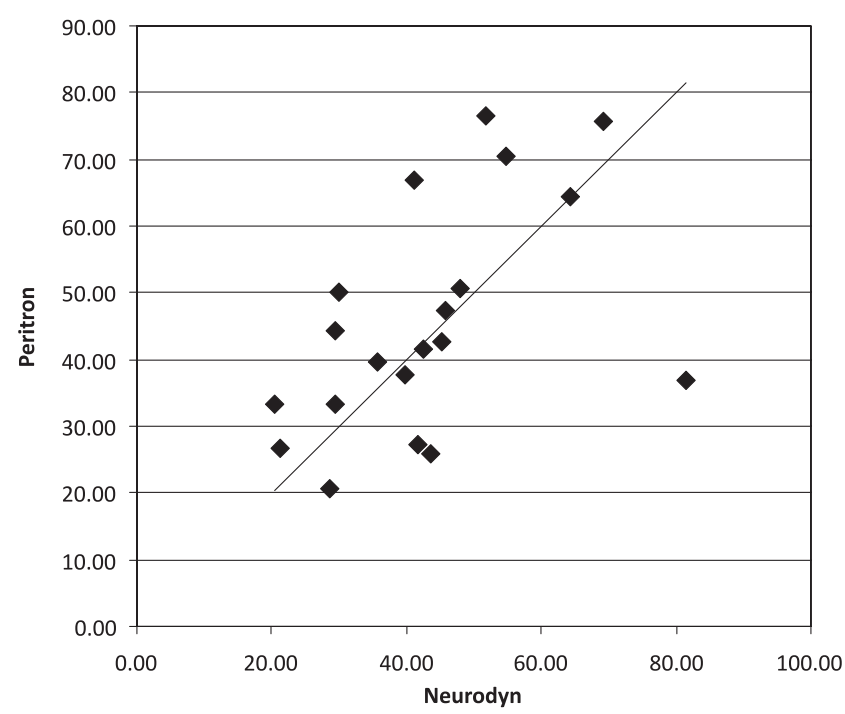

Figure 1 - Concordance in the measurements of intravaginal pressure using the vaginal Neurodyn and Peritron perineometers in twenty voluntary nulliparous women

including the difference in the length and diameter of the probes, differences in materials, equipment parameters, the positioning of the probe, the order in which the devices were tested, potential improvements in PFM contractions, and muscle fatigue.

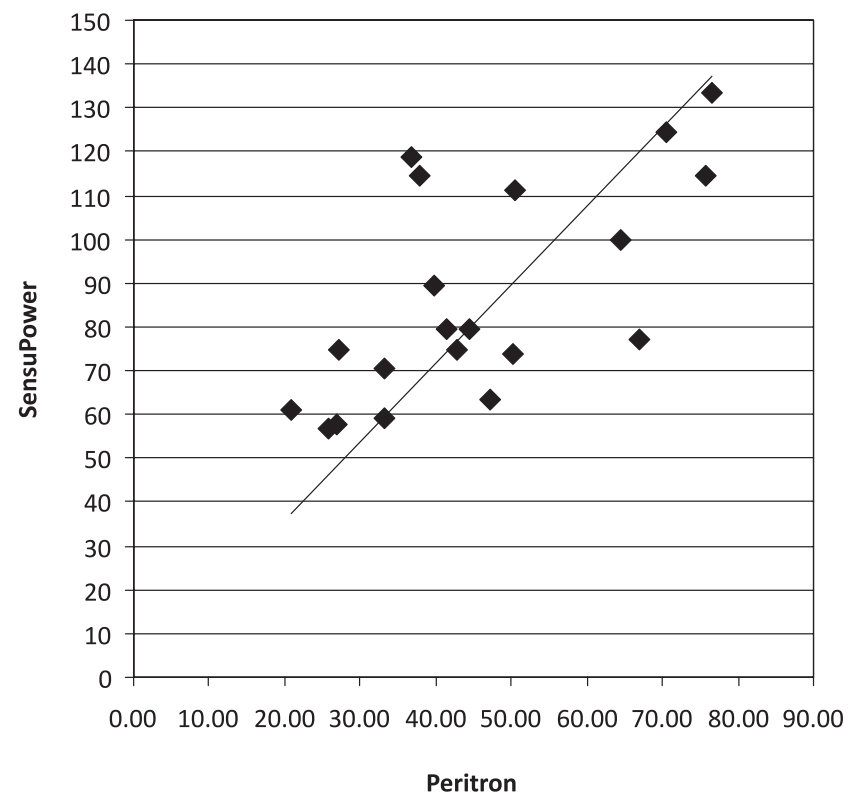

Figure 2 - Concordance in the measurements of intravaginal pressure using the vaginal Peritron and SensuPower perineometers in twenty voluntary nulliparous women

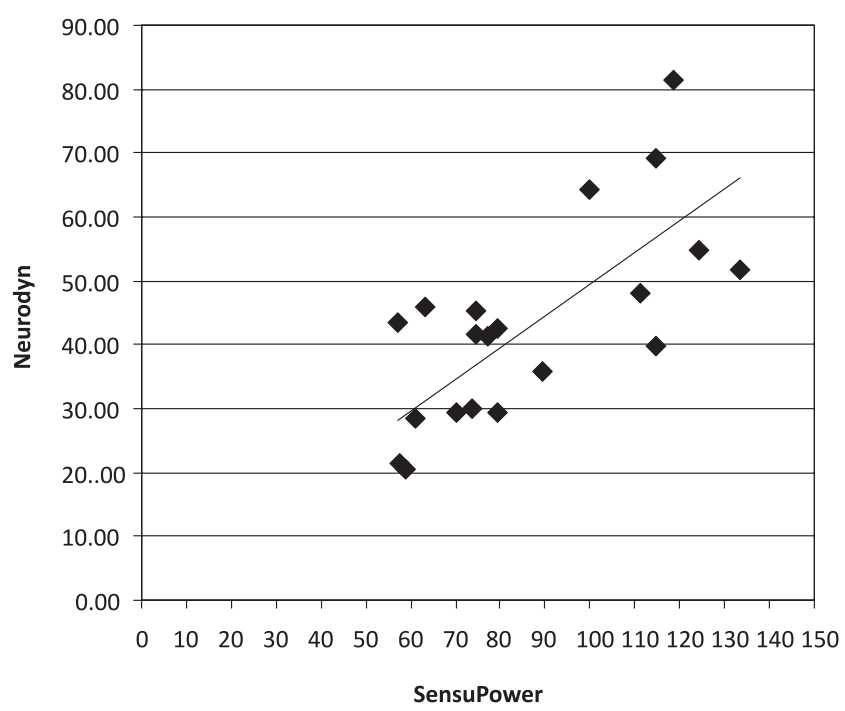

Figure 3 - Concordance in the measurements of intravaginal pressure using the vaginal SensuPower and Neurodyn perineometers in twenty voluntary nulliparous women

Both this study and the study by Bo et al. $(2005)^{21}$ identified differences in the measurements that were obtained by instruments with probes of different lengths and diameters. Although the probes that were evaluated by Bo et al. $(2005)^{21}$ exhibited greater variations in size and diameter than those evaluated in this study, the correlation identified between the Neurodyn ${ }^{\mathrm{TM}}$ (Ibramed, Brazil) and Sensupower ${ }^{\mathrm{TM}}$ (Kroman, Brazil) models was poor, fair between the Peritron ${ }^{\mathrm{TM}}$ (Cardio-Design, Australia) and Sensupower ${ }^{\mathrm{TM}}$ (Kroman, Brazil) models, and moderate between the Peritron ${ }^{\mathrm{TM}}$ (Cardio-Design, Australia) and 
Neurodyn $^{\mathrm{TM}}$ (Ibramed, Brazil) models. The different physical characteristics of the tested devices may have contributed to these results, since the different materials respond differently to the same pressure. According to the information published on the websites of the manufacturers and distributors, the Neurodyn $^{\mathrm{TM}}$ (Ibramed, Brazil), SensuPower ${ }^{\mathrm{TM}}$ (Kroman, Brazil) and Peritron ${ }^{\mathrm{TM}}$ (Cardio-Design, Australia) models feature latex, nontoxic PVC and silicone rubber catheters, respectively. In addition, other parameters, such as the sensitivity of each instrument to pressure, may influence the measurements. In this study, brand new equipment was used, with calibrations certified by the manufacturers and within the warranty period. However, we did not quantify the differences in the sensitivity of each piece of equipment to intra-vaginal pressure. ${ }^{21}$

The position of the probe inside the vagina is another factor that may impact the respective measurements because the pressure values vary across different regions of the vagina. ${ }^{21,24,25}$ In this study, although the equipment featured probes of different lengths, the examiner positioned the middle of each catheter $3.5 \mathrm{~cm}$ within the vagina, at the point of greatest pressure as identified in a prior study. ${ }^{26}$ Despite efforts to standardize the positioning of the probe as much as possible, there exist individual variations, such as the length and width of the vagina, that may result in different measurements of the intra-vaginal pressure. Such aspects were minimized by including in our study only nulliparous women and women who had never been pregnant. Another factor that may generate invalid data was elevated intraabdominal pressure concomitant with PFM contractions. The Valsalva maneuver frequently occurs while trying to contract the PFM, producing an elevated reading for the intra-vaginal pressure that does not match the pressure increase that is produced by the PFM alone. ${ }^{26}$ Therefore, the observation of the cranial movement of the probe of the perineometer into the vagina and the inclusion of only women who were able to correctly contract the PFM were important criteria that were used in this study, with the goal of eliminating any measurements that do not reflect the contraction of the PFM.

In the study by Bo et al. (2005), ${ }^{21}$ the equipment with the highest probe caliber was the last one that was tested, with the justification that its use may temporarily enlarge the vaginal canal and make it more difficult for the patient to achieve maximum contraction. The researchers argued that this would lead to lower perineometer measurements in subsequent tests - in that study, the various hardware brands were tested on consecutive days. In the present study, there was no such concern since we included a non-test rest day between each test episode. However, the hypothesis that the use of a probe of a larger diameter may hinder the maximum muscle contraction was not substantiated by Bo et al. (2005) ${ }^{21}$ who reported higher values of contraction with the use of the larger-diameter perineometer that was tested last.

These results are partially corroborated by the findings of this study, since the measurements that were obtained with the Peritron ${ }^{\mathrm{TM}}$ (Cardio-Design, Australia), with a probe of $2.8 \mathrm{~cm}$ diameter, were lower than those obtained from the SensuPower ${ }^{\mathrm{TM}}$ (Kroman, Brazil), which had a probe of $3 \mathrm{~cm}$ diameter. However, the results obtained with the Neurodyn ${ }^{\mathrm{TM}}$ (Ibramed, Brazil), which had a probe of $3.2 \mathrm{~cm}$ in diameter, were lower than those measured with the SensuPower ${ }^{\mathrm{TM}} 3$ $\mathrm{cm}$ diameter probe (Kroman, Brazil). These data support the conclusion that the acquisition of higher or lower measurement values depends not only on the diameter of the probes used but also on other variables, such as individual vaginal diameter and the consistency of each probe. Although the probe diameters were similar, but not identical, the results were quite different, suggesting that perhaps the use of probes of the same diameter with different materials and instruments also leads to variable measurements. If different equipment with probes of the same diameter were to yield identical readings, the comparison of results would be a relatively easy problem to solve. This hypothesis should be tested in future studies using different instruments with probes of identical size.

Other reports indicate that both an improvement in contraction performance and muscle fatigue may influence the data from the final day of testing. ${ }^{21}$ The possibility of muscle fatigue was discussed in the study by Bo et al. (2005), ${ }^{21}$ with regard to the results that were obtained using the Peritron ${ }^{\mathrm{TM}}$ (Cardio-Design, Australia) perineometer, which was tested one day after the use of a fiberoptic microtip transducer (Camtech AS, Norway). This study suggested higher values for the Peritron measurements, a result that was explained by the authors in terms of improvements in muscle response during the second evaluation.

Seeking to eliminate the possibility of muscle fatigue, this study tested only one brand of equipment each day, with a day of rest before each subsequent assessment. Although some volunteers reported that they felt that they achieved stronger contractions on the last day, the values were not significantly higher during the last assessment. Our research makes it possible to compare the results from two Brazilian brands of perineometers with a foreign brand that is widely used in international studies. Despite the fact that the concordance was not very strong between all three evaluated brands, the concordance was better between the national brands and the foreign product, than it was between the national brands alone. There is still a need for studies to assess the intra- and interexaminer reliability of the examination of each of the national 
brands. Several other issues, such as the ideal size of probes to measure variations in the size of the vagina, still need to be elucidated for future studies.

Despite the fact that the conversion of units of measurement in $\mathrm{mmHg}$ and psi into $\mathrm{cmH}_{2} \mathrm{O}$ is trivial, ${ }^{27}$ any efforts by the manufacturers to standardize units of measurement would make it much easier to compare the results. In this study, our greatest difficulty was the need to convert a custom unit of measurement that was created by the manufacturer of the Sensupower ${ }^{\mathrm{TM}}$ device (Kroman, Brazil), namely, Sauers. We were unable to find a direct conversion ratio to translate Sauers into $\mathrm{cmH}_{2} \mathrm{O}$, and the manufacturer's manual only lists five values of Sauers with their equivalents in psi. We used these values to create a linear regression, assuming that a linear relationship exists between the two measures. Another set of linear regressions was performed to convert psi into $\mathrm{cmH}_{2} \mathrm{O}$. The assumption behind any linear regression is that the residuals exhibit a normal distribution with zero mean and constant variance. Since this assumption held true in our work, we consider our approach to be justified. ${ }^{28}$

Since this research identified significant variability between the results from the three different brands of investigated perineometers, we would recommend the use of the same brand of instruments whenever the goal is to compare the results or combine them for meta-analysis. This is important both in clinical practice for the assessment and reassessment of patients and in research that involves sequential clinical measurements.

\section{CONCLUSION}

We conclude that there exists a moderate concordance between the results obtained with the Peritron ${ }^{\mathrm{TM}}$ (CardioDesign, Australia) and Neurodyn ${ }^{\mathrm{TM}}$ (Ibramed, Brazil) perineometers, a fair concordance between the Peritron ${ }^{\mathrm{TM}}$ (Cardio-Design, Australia) and SensuPower ${ }^{\mathrm{TM}}$ (Kroman, Brazil) brands and a poor concordance between the Neurodyn $^{\mathrm{TM}}$ (Ibramed, Brazil) and SensuPower ${ }^{\mathrm{TM}}$ (Kroman, Brazil) products.

\section{ACKNOWLEDGMENT}

\section{FAPESP}

\section{REFERENCES}

1. Menta S, Schirmer J. Relação entre a pressão muscular perineal no puerpério e o tipo de parto. Rev. Bras. Ginecol. Obstet. 2006;28:523

2. Rett MT, Simões JÁ, Herrmann V, Marques AA, Morais SS. Existe diferença na contratilidade da musculatura do assoalho pélvico feminino em diversas posições? Rev. Bras. Ginecol. Obstet. 2005;27:12-9.

3. Bo K, Finckenhagen HB. Is there any difference in measurement of pelvic floor muscle strength in supine and standing position? Acta Obstet Gyn Scan. 2003;82:1120-4

4. Moreira SFS, Girao MJBC, Sartori MGF, Baracat EC, Lima GR Mobilidade do colo vesical e avaliação funcional do assoalho pélvico em mulheres continentes e com incontinência urinária de esforço, Consoante o Estado Hormonal. Rev. Bras. Ginecol. Obstet. 2002;24:365-70.

5. Bo K, Finckenhagen HB. Vaginal palpation of pelvic floor muscle strength: inter-test reproducibility and comparison between palpation and vaginal squeeze pressure. Acta Obstet Gyn Scan. 2001;80:883-7.

6. Barbosa AMP, Carvalho LR, Martins AMVC, Calderon IMP, Rudge MVC. Efeito da via de parto sobre a força muscular do assoalho pélvico. Rev. Bras. Ginecol. Obstet. 2005;27:677-82.

7. Frawley HC, Galea MP, Phillips BA, Sherburn M, Bo K. Reliability of Pelvic Floor Muscle Strength Assessment Using Diferent Test Positions and Tools. Neurourol Urodyn. 2006;25:236-42.

8. Benvenuti F, Caputo GM, Bandinelli S. Reeducative treatment of female genuine stress incontinence. Am J Phys Med. 1987;66:155-68.
9. Bo K, Larsen S, Oseid S. Knowledge about and ability to correct pelvic foor muscle exercises in women with urinary stress incontinence. Neurourol Urodyn. 1988;7:261-2.

10. Bump R, Hurt WG, Fantl JA, Wyman J. Assessment of Kegel exercise performance after brief verbal instruction. Am J Obstet Gynecol. 1991;165:322-9.

11. Bø K. Pelvic Floor Muscle Strength and Response to Pelvic Floor Muscle Training for Stress Urinary Incontinence. Neurourol Urodyn. 2003;22:654-8.

12. Kerschan-schindl K, Uher E, Wiesinger G, Kaider A, Ebenbichler G, Nicolakis P, et al. Reliability of Pelvic Floor Muscle Strength Measurement in Elderly Incontinent Women. Neurourol Urodyn. 2002;25:42-7.

13. Hundley AF, Wu JM, isco AG. A comparison of perineometer to brink score for assessment of pelvic floor muscle strength. Am J Obstet Gynecol. 2005;192:1583-91.

14. Frawley H, Galea M, Phillips B, Sherburn M, Bo K. Effect of test position, using two different methods of measurement, on reliability of pelvic floor strength assessment. Abstract number 542. Papers to be read by title. ICS/IUGA Annual Meeting, Paris, 2004.

15. Bo K, Kvarstein B, Hagen R, Larsen S. Pelvic floor muscle exercise for the treatment of female stress urinary incontinence: I. Reliability of vaginal pressure measurements of pelvic floor muscle strength. Neurourol Urodyn. 1990;9:471-7. 
16. Bo K, Kvarstein B, Hagen R, Larsen S. Pelvic floor muscle exercise for the treatment of female stress urinary incontinence: II. Validity of vaginal pressure measurements of pelvic floor muscle strength and the necessity of supplementary methods for control of correct contraction. Neurourol Urodyn. 1990;9:479-87.

17. Bump R, Mattiasson A, Bo K, Brubaker L, DeLancey J, Klarskov P, et al. The standardization of terminology of female pelvic organ prolapse and pelvic floor dysfunction. Am J Obstet Gynecol. 1996;175:10-7.

18. Sapsford R, Hodges P, Richardson C, Cooper D, Markwell S, Jull G. Co-activation of the abdominal and pelvic floor muscles during voluntary exercises. Neurourol Urodyn. 2001;20:31-42.

19. Critchley D. Instructing pelvic floor contraction facilitates transversus abdominis thickness increase during low-abdominal hollowing. Physiother Res Int. 2002;7:65-75.

20. Neumann P, Gill V. Pelvic floor and abdominal muscle interaction: EMG activity and intra-abdominal pressure. Int Urogynecol J Pelvic Floor Dysfunct. 2002;13:125-2.

21. $\mathrm{B} \emptyset \mathrm{K}, \mathrm{Raastad} \mathrm{R}$, Finckenhagen HB. Does the size of the vaginal probe affect measurement of pelvic floor muscle strength? Acta Obstet Gyn Scan. 2005;84:129-33.
22. Lin LI. A A concordance correlation coefficient to evaluate reproducibility. Biometrics. 1989;45:255-68.

23. Altman DG. Practical statistics for medical research. London: Chapman \& Hall. 1997.

24. Guaderrama NM, Nager WC, Liu J, Pretorius DH, Mittal RK. The vaginal pressure profile. Neurourol Urodyn. 2005;24:243-7.

25. Bo K. Pressure measurements during pelvic floor muscle contractions: the effect of different positions of the vaginal measuring device. Neurourol Urodyn. 1992;11:107-13.

26. Bo K. Pelvic floor physical therapy in elite athletes. In: Bo K, Berghmans B, orkved S, Van Kampen M, editors. Evidence-based physical therapy for the pelvic floor - Bridging science and clinical practice. $1^{\mathrm{a}} \mathrm{ed}$. China: Elsevier, 2007; p. 369-78.

27. INMETRO (BR). DOQ-CGCRE-014 - Orientações para a realização de calibração de medidores digitais de pressão. Documento de caráter orientativo. Rio de Janeiro, fev. 2008.

28. Montgomery DC. Design and Analysis of Experiments, $5^{\mathrm{a}}$ ed, Nova Iorque: John Wiley \& Sons, 2000. 
